\title{
Algoritmo de Alocação Dinâmica de Banda para Rede Óptica de Acesso GPON
}

\author{
Alex F. Santos, Sandro M. Rossi e Amílcar C. César
}

\begin{abstract}
Resumo- Neste artigo descrevemos um algoritmo de alocação dinâmica de banda para rede óptica passiva (PON) de acesso padrão GPON. $O$ algoritmo classifica o tráfego gerado em 16 ONUs (optical network unit) em 4 contêineres de tráfego (T-CONT) para transmissão upstream, aloca banda mínima para as ONUs e distribui a banda não utilizada de acordo com critério baseado em três prioridades. A taxa de bit upstream é 1,25 Gbps. $O$ desempenho do algoritmo é analisado com base na variação do atraso de pacotes em função do tráfego gerado nas ONUs. Os resultados obtidos por meio de simulação computacional mostram a versatilidade do algoritmo.
\end{abstract}

Palavras-Chave- Passive optical network (PON), Gigabit PON (GPON), alocação dinâmica de banda.

\begin{abstract}
In this article we describe an algorithm for dynamic bandwidth assignment (DBA) for gigabit passive optical network (GPON). The algorithm classifies the traffic generated in 16 ONUs in four GPON traffic containers (TCONT) for upstream transmission, assigns minimum bandwidth for ONUs, and assigns bandwidth not in use for ONUs based on three priorities. The upstream bit rate is $\mathbf{1 . 2 5}$ Gbps. The performance of the algorithm is analyzed based on the variation of the packet delay as a function of the traffic generated in ONUs. The results obtained by computational simulation show the versatility of the algorithm.
\end{abstract}

Index Terms - Passive optical network (PON), Gigabit PON, dynamic bandwidth assignment (DBA).

\section{INTRODUÇÃO}

As redes de acesso têm se tornado objeto de intensa expansão e oferta de tecnologias. Comparadas com as redes metropolitanas e de longa distância, a infraestrutura próxima do usuário, também conhecida inicialmente como "last mile" e recentemente "first mile," tem sido um gargalo para a oferta de serviços de banda larga. Destacam-se os sistemas eletrônicos wireline, como x-DSL (digital subscriber line) e HFC (hybrid fiber-coax, cable modem), e wireless, como 3G, WiMAX e WiFi. Estas redes ocupam nichos tecnológicos atraentes, especialmente as que oferecem mobilidade.

No entanto, estima-se que em futuro não muito distante as residências de usuários necessitarão de acesso com banda de 70 a 100 Mbps na direção downstream e 20 a 30 Mbps na direção upstream [1]. Esta banda downstream é capaz de acomodar canais HDTV (high-definition television) e SDTV

Alex F. Santos (afsantos@sel.eesc.usp.br) e Amílcar C. César (amilcar@sel.eesc.usp.br), Universidade de São Paulo, EESC, Depto. de Eng. Elétrica, Av.Trabalhador São-carlense, 400, 13566-590 São Carlos, SP, Brasil. Sandro M. Rossi (sandro@cpqd.com.br), Fundação CPqD Centro de Pesquisa e Desenvolvimento em Telecomunicações, Rodovia Campinas - Mogi-Mirim, km 118,5, 13086-902 Campinas, SP, Brasil. Esta pesquisa foi parcialmente financiada pela CAPES, CNPq e CPqDFUNTTEL. (standard-definition television), navegação na Internet, VoIP (voice over Internet protocol), jogos on line e outros serviços banda larga.

A PON (passive optical network) é uma arquitetura de rede de acesso ponto-multiponto que utiliza divisores (splitters) de sinal óptico para que vários usuários sejam atendidos por uma fibra óptica. A arquitetura é mais econômica e a utilização da largura de faixa da fibra óptica é excelente alternativa para resolver a demanda de banda. A configuração é formada por terminal de linha óptica (OLToptical line terminal), localizada na central do provedor de serviço, e unidade de rede óptica (ONU - optical network unit), localizada perto do usuário [2].

A transmissão no sentido downstream, da OLT para as ONUs, é realizada por meio de difusão (broadcast). Cada ONU identifica seu tráfego por meio de endereçamento. No sentido upstream, das ONUs para a OLT, a transmissão é realizada utilizando acesso múltiplo por divisão de tempo (TDMA - time division multiple access), compartilhando o meio de transmissão. Comprimentos de onda distintos são utilizados para a transmissão nos dois sentidos.

Há dois padrões de arquitetura PON: o EPON (Ethernet PON), regulamentado pela norma IEEE 802.3ah [3], e o GPON (Gigabit PON), regulamentada pela norma ITU-T G.984 [4]. O padrão EPON utiliza o protocolo Ethernet e o GPON o método de encapsulação GEM (GPON encapsulating method) que suporta quadros ATM (asynchronous transfer mode) e Ethernet [4]-[6]. A taxa de bit máxima do padrão GPON é 2,5 Gbps e do EPON é 1 Gbps. A intensa demanda de banda poderá ainda ser atendida por esquemas WDM (wavelength division multiplexing)-PON. O próximo patamar de taxa dos dois padrões será $10 \mathrm{Gbps}$.

O padrão EPON tem sido o preferido pelas operadoras de redes de acesso do sudeste asiático, enquanto o GPON tem sido escolhido principalmente por operadoras européias e norte-americanas. A tendência das operadoras brasileiras é também utilizar o padrão GPON para acesso via fibra óptica.

O padrão GPON classifica o tráfego upstream nas ONUs em 4 tipos e os reúne em 5 contêineres (T-CONT). O TCONT 1 agrupa tráfego CBR (constant bit rate); o T-CONT 2, tráfego VBR (variable bit rate); o T-CONT 3, tráfego em rajada que exige banda mínima garantida; o T-CONT 4, tráfego best-effort ; o T-CONT 5, combinação de tráfego de outros contêineres. A sequência dos T-CONTs indica a prioridade de tráfego para transmissão na direção upstream.

A quantidade de time slots (TDMA) necessários para que as ONUs efetuem a transmissão no sentido upstream é designado pelo mapa de banda, que é transmitido pela OLT na direção downstream.

A norma GPON estabelece o protocolo MAC (medium access control) para o compartilhamento do meio de 
transmissão na direção upstream e fornece esquema de operação do algoritmo de alocação de banda (time slots) [4][6]. Sendo assim, vários algoritmos de alocação de banda têm sido propostos, destacando-se os que atuam de forma dinâmica (DBA — dynamic bandwidth allocation) [7]-[10].

Dentre os DBAs para padrão GPON destaca-se o algoritmo DMB (dynamic minimum bandwidth) [7], [8], que aloca banda mínima para cada ONU. A banda eventualmente não-utilizada pelas ONUs é realocada para os T-CONTs de prioridade mais alta (tráfego sensível a atraso) com base em fator de quantidade de banda para distribuição entre as ONUs. No caso de protocolos para o padrão EPON destacase o IPACT (interleaved polling with adaptive cycle time) [11].

Em geral, os algoritmos alocam banda de acordo com as informações de $\mathrm{CoS}$ (class of service), QoS (quality of service) e SLA (service level agreement). Os 5 T-CONTs do padrão são as indicações de $\mathrm{CoS}$; QoS é um conjunto de requisitos de qualidade, como banda e atraso de pacotes; SLA é um conjunto de especificações de serviços e prioridades, negociado entre provedor e usuário, e que pode utilizar informações de CoS e QoS.

A administração da banda máxima na direção upstream é baseada na banda mínima (CIR - committed information rate), que é garantida para todas as ONUs, na banda que uma conexão pode dispor acima da CIR (PIR - peak information rate) e na banda disponível para realocação (EIR - excess information rate), que é a diferença entre a PIR e a CIR [5].

Neste artigo descrevemos um algoritmo de alocação dinâmica de banda para rede de acesso por fibra padrão GPON e operando com taxa de bit upstream 1,25 Gbps. O algoritmo organiza as filas de tráfego gerado em 16 ONUs de acordo com as especificações de 4 T-CONTs (CoS). Não utilizamos o T-CONT 5.

$\mathrm{O}$ algoritmo proposto neste artigo estende as funcionalidades do DMB [7], [8], realocando banda com base em três SLAs, que indicam a prioridade das ONU para receber a banda que restou após a alocação da banda garantida para todas as ONUs. Assim, os pacotes upstream nas ONUs são classificados de acordo com o tipo (CoS) e enfileirados nos respectivos T-CONTs para transmissão de acordo com a prioridade de tráfego estabelecida no padrão GPON. Portanto, CoS reúne informações dos T-CONTs, QoS indica a banda a ser realocada e o SLA a prioridade das ONUs para receber a banda realocada. O desempenho do algoritmo é avaliado por meio da variação do atraso médio de pacote em função do tráfego. Comparação de desempenho com algoritmo IPACT para EPON é realizada para efeito de validação do algoritmo, já que o IPACT se tornou pelo uso padrão de comparação.

\section{TOPOLOGIA DA REDE}

A Figura 1 mostra a topologia da rede de acesso PON e um exemplo de sincronização de transmissão de tráfego upstream gerado por ONUs.

A Figura 2 mostra o quadro GPON downstream. A OLT administra a banda de acordo com a solicitação de cada ONU e critérios especificados pelo DBA. O GPON aproveita melhor a banda do que o EPON porque não troca mensagens de solicitação e autorização de transmissão separadamente para cada ONU.

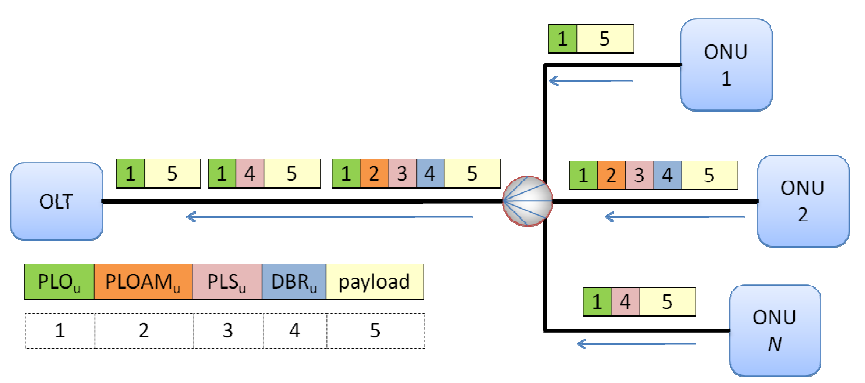

Figura. 1. Exemplo de transmissão de tráfego na direção upstream em padrão GPON e campos de controle. No campo $\mathrm{DBR}_{\mathrm{u}}$ a $\mathrm{ONU}$ informa o status da fila, solicitando time slots. OLT: Optical line terminal; ONU: Optical network unit; PLO: Physical layer overhead (obrigatório em todas as transmissões); PLOAM: Physical layer operations, administration, and maintenance; PLS: power leveling sequence; DBR: dynamic band report; u: upstream [5].

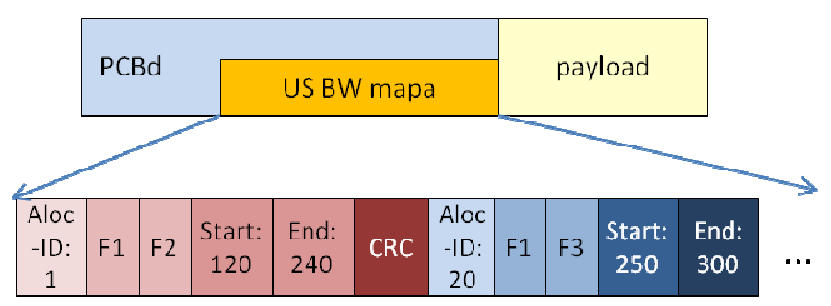

Figura 2. Quadro downstream GPON. O campo mapa de mensagem de banda (US BW) indica o início e término de transmissão de cada ONU de acordo com o status das filas e critério de alocação de time slots. PCB: Physical control block; USBW: Upstream bandwidth; Aloc-ID: Especificação de fila de uma ONU; F: Flag. Posição de transmissão dos campos PLOAM, PLS, DBR; d: downstream [5].

\section{A. Transmissão de Pacotes em Padrão GPON}

A duração do quadro nas direções downstream e upstream é $125 \mu \mathrm{s}$. Para enviar os pacotes durante este intervalo o tamanho máximo para cada taxa (1,25 e 2,5 Gbps) é 19440 e 38880 bytes, respectivamente [5]. No campo US_BW_mapa está indicada a quantidade de bytes que cada ONU pode transmitir. De acordo com estas informações, os pacotes upstream são organizados e enviados para a OLT.

A banda para as ONUs pode ser arbitrada segundo o exemplo de [12]. Em uma rede GPON com 16 ONUs, um TCONT e taxa de 1,25 Gbps, o tamanho de cada time slot é 19440 bytes, disponíveis para toda a transmissão upstream. Assim, cada ONU pode transmitir 1215 bytes em cada transmissão upstream, dos quais 17 bytes são utilizados pelo cabeçalho e 1198 bytes são utilizados para transmissão de conteúdo (payload).

\section{B. Modelagem de Tráfego}

O tráfego em redes de acesso operando sob padrões GPON e EPON consiste de rajadas, caracterizado por períodos ON (rajadas) e OFF (ausência de rajadas) [7]-[12]. Este tipo de tráfego exibe autossimilaridade, sendo seu grau dado pelo parâmetro Hurst [7]-[12]. Em nossa implementação este fator é 0,8 . 


\section{Classe de Serviço, Qualidade de Serviço E CONTRATO DE SERVIÇO}

Os vários tipos de tráfegos, como voz, vídeo, dados, correio eletrônico e navegação em páginas Web, são classificados em ordem de prioridade para serem transmitidos. Esta classificação é a CoS (T-CONTs). Em caso de congestionamento, o protocolo MAC utiliza a informação de CoS para disciplinar a transmissão, aguardar em fila ou descartar pacotes, caso seja necessário. A classificação indica a ordem de prioridade de transmissão, conforme ilustra a Figura 3, e não distingue ONUs, mas sim o tipo de tráfego.

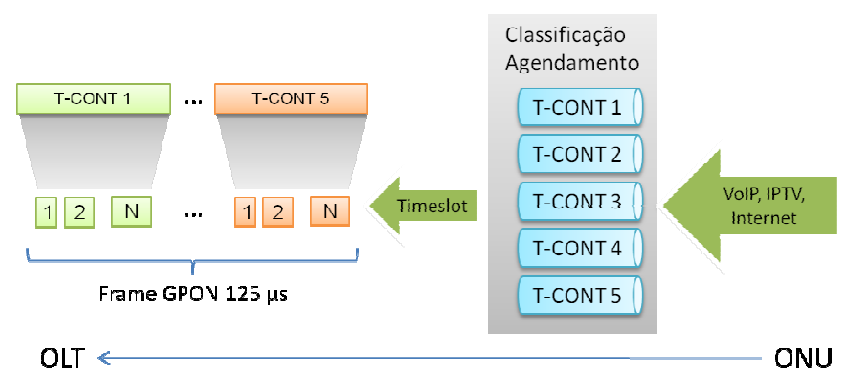

Figura 3. Esquema da operação classificação de tráfego das ONUs em TCONTs e agendamento de transmissão na direção upstream.

O ITU-T 984.3 [5] especifica 5 T-CONTs para o padrão GPON:

T-CONT 1: Alocação fixa de banda; adequado para aplicações que utilizam taxas fixas de transmissão e que sejam sensíveis a atraso e variação de atraso, como serviços CBR (constant bit rate);

T-CONT 2: Alocação garantida de banda; adequado para tráfego com taxa média bem definida e com pouca sensibilidade a atraso e variação de atraso, como serviços VBR (variable bit rate);

T-CONT 3: Alocação garantida de banda com possibilidade de disputar mais banda; adequado para tráfego de rajada e que necessita de uma banda mínima garantida;

T-CONT 4: Alocação de banda do tipo best-effort; adequado para tráfego de rajada insensível a atraso;

T-CONT 5: Serviços combinados de todos ou alguns T-CONTs.

O mecanismo CoS não garante qualidade de serviço, como atraso máximo ou banda. A garantia destas especificações é dada pela QoS, que é um conjunto de requisitos de qualidade de transmissão como banda, atraso, jitter, probabilidade de perda de pacote e taxa de erro. O protocolo que implementa QoS pode utilizar informações de $\mathrm{CoS}$ para escolher recursos que garantam qualidade de transmissão. No entanto, para que isto seja feito, os provedores especificam por meio do SLA os serviços, prioridades, responsabilidades, garantias e penalidades. As cláusulas do SLA incluem a identificação e definição das necessidades do usuário, fornecimento de estrutura (framework) para estabelecimento do acordo, simplificação de problema complexo, redução da área de conflito e eliminação de expectativa irrealista. Ele especifica nível de serviço, desempenho e operação. $\mathrm{O}$ acordo é baseado na qualidade de serviço que o usuário recebe e não em condições que o provedor entrega o serviço. As especificações constantes do QoS normalmente fazem parte do acordo.

A CIR é a banda contratada e garantida. Em qualquer instante e em operação normal, a banda disponível destinada a um usuário nunca está abaixo deste valor. A soma da CIR alocada para os usuários geralmente é no máximo igual à capacidade do sistema. A PIR é a banda que uma conexão pode dispor acima da CIR. Ela é oferecida a uma conexão somente quando não há congestionamento. A PIR é concedida a um ou mais usuários se houver banda disponível depois que todas as CIRs são atendidas. A PIR alocada a um ou a todos os usuários não pode exceder a capacidade do enlace. A EIR é a diferença entre a PIR e a CIR. É a banda disponível para alocação dinâmica depois que todos os usuários tenham sido atendidos pela CIR.

Neste trabalho utilizamos especificações mínimas para CoS, QoS e SLA. A CoS é dada pelos T-CONTs do padrão GPON, a QoS é a garantia de alocação de banda mínima (CIR) e o SLA fornece a prioridade para alocação da banda não utilizada (EIR).

\section{Algoritmo de AlocaÇÃo de LARGURA DE BANDA}

O algoritmo DMB [7]-[8] foi proposto para gerenciar a alocação dinâmica de banda para os contêineres a partir da prioridade mais alta. Entretanto, aquele algoritmo realoca banda não-utilizada para os contêineres, mas não distingue prioridades entre ONUs.

Em nossa abordagem, o algoritmo classifica o tráfego de acordo com o padrão GPON, aloca a mesma banda mínima para todas as ONUs e distribui a banda não utilizada de acordo com as prioridades:

SLA $\mathbf{A}_{1}$ : Prioridade alta. As ONUs que se enquadram nesta classe têm prioridade de banda sob as demais;

$\mathbf{S L A}_{2}$ : Prioridade média. A banda que não foi alocada no $\mathrm{SLA}_{1}$ será alocada para as ONUs deste SLA;

SLA : Prioridade baixa. Se ainda houver banda disponível, depois de atendidas as ONUs de $\mathrm{SLA}_{1}$ e $\mathrm{SLA}_{2}$, ela será alocada para este SLA.

$\mathrm{O}$ algoritmo proposto estabelece a fila de T-CONTs, sendo enviado primeiramente o tráfego do T-CONT de prioridade mais alta. Primeiramente, ele aloca banda garantida (CIR) para todas as ONUs e em seguida realocada dinamicamente a EIR para as ONUs que necessitam de banda além da CIR, sendo atendido primeiramente o SLA de maior prioridade. A banda realocada obedece à prioridade dos T-CONTs do padrão GPON.

A Figura 4 ilustra o fluxograma do algoritmo implementado. De acordo com ele, o algoritmo aloca a banda garantida para todas as ONUs. Se a soma da banda garantida for igual à banda total da rede não haverá EIR para ser alocada dinamicamente para as ONUs. No entanto, se houver EIR, ela será alocada para as ONUs de SLA . Posteriormente, se ainda houver banda, aloca-se para as ONUs de $\mathrm{SLA}_{2}$. Por fim, aloca-se banda para as ONUs de $\mathrm{SLA}_{3}$. 


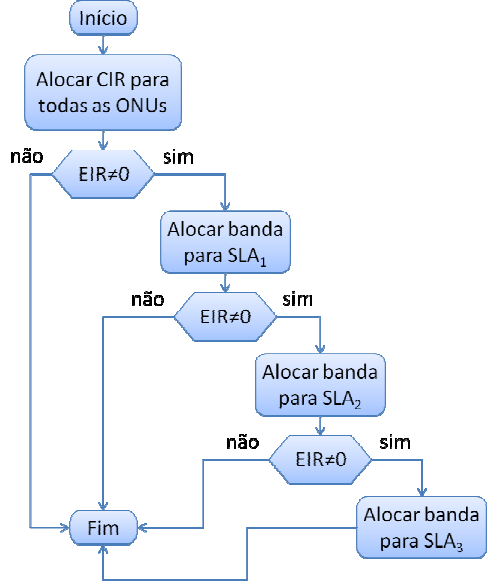

Figura 4. Fluxograma do algoritmo proposto neste trabalho. CIR Committed information rate; EIR: Excess information rate; SLA: Service

level agreement.

\section{RESUlTADOS NUMÉRICOS}

Nesta seção são apresentados os resultados da simulação computacional de rede de acesso GPON. Eles foram baseados em topologia PON padrão GPON formada por uma OLT e 16 ONUs. A distância entre OLT e ONUs é estabelecida por sorteio, com base em variável aleatória, não excedendo $20 \mathrm{~km}$, conforme estabelece a norma. Assim, o tempo de ida-e-volta (RTT - round-trip time) do sinal é diferente para cada ONU.

O primeiro resultado é a comparação de desempenho entre redes GPON e EPON. Para tanto, será utilizado o algoritmo IPACT. Posteriormente, o desempenho de rede GPON com 16 ONUs é avaliado por meio da variação do atraso de pacote em função do tráfego gerado nas ONUs.

\section{A. Algoritmo IPACT para EPON}

O padrão EPON não especifica o algoritmo de gerenciamento e alocação de banda e diversos algoritmos de alocação dinâmica foram propostos na literatura [11], [12], com destaque para o algoritmo "interrogação intercalada com ciclos de tempos adaptativos (IPACT)" [11].

Este algoritmo utiliza a informação do tamanho da fila do buffer para alocar dinamicamente a banda. O esquema interrogação intercalada troca informações dentro da banda. Mensagens gate (autorização para transmissão) e report (informação de estado da fila) são trocadas entre cada ONU e OLT em processo cíclico de interrogação.

\section{B. Comparação de Desempenho}

Uma rede EPON é comparada com uma rede GPON equivalente utilizando o algoritmo IPACT. A adaptação para as redes GPON pode ser realizada com a alteração da estrutura dos pacotes e forma de transmissão das mensagens gate e report (do padrão EPON) entre OLT e ONUs [7]. Nas transmissões upstream, as redes GPON utilizam o campo DBRu no início de cada time slot para enviar a solicitação de banda para o OLT. A transmissão das ONUs forma o quadro upstream. Por outro lado, nas redes EPON a transmissão é realizada enviando a mensagem report ao final de cada transmissão da ONU. No sentido downstream as redes EPON enviam, durante o ciclo de interrogação, uma mensagem gate, enquanto nas redes GPON uma mensagem equivalente é enviada às ONUs apenas no início de cada ciclo por meio do campo US_BW_Mapa. O intuito desta simulação é avaliar se o atraso médio na transmissão dos pacotes das redes EPON e GPON é equivalente [7]. Logo, o único parâmetro a ser alterado na comparação é o tempo de guarda entre as transmissões que seguem os dois padrões [3], [5]. Para esta comparação foram utilizados os parâmetros mostrados na Tabela 1 .

Tabela 1. Parâmetros de simulação do algoritmo IPACT para EPON e GPON.

\begin{tabular}{lcc} 
Descrição & EPON & GPON \\
\hline Taxa de bit total (Mbps) & 1000 & 1000 \\
Taxa de bit ONU (Mbps) & 100 & 100 \\
Número Total de ONUs & 16 & 16 \\
Tamanho do buffer nas ONUs (MB) & 10 & 10 \\
Distância máxima entre OLT e ONUs (km) & 20 & 20 \\
Tamanho máximo do time slot (B) & 15000 & 15000 \\
Tempo (bit) de guarda entre transmissões & $5 \mu \mathrm{s}$ & 96 bit \\
Tempo máximo do ciclo de interrogação (ms) & 2 & 2 \\
\hline
\end{tabular}

A Figura 5 mostra o atraso médio dos pacotes gerados nas ONUs das redes EPON e GPON em função do tráfego. Este gráfico de desempenho é típico de redes de acesso PON. Para baixos valores de tráfego, o atraso médio é pequeno porque a banda disponível upstream é suficiente para atender o tráfego gerado. Neste caso, o buffer está relativa ou totalmente vazio. A partir de um determinado valor de tráfego oferecido à rede pelas ONUs, as filas aumentam e o buffer passa a ser mais utilizado. Assim, para o caso de 16 ONUs, se a soma do tráfego gerado por cada uma delas é $0,9 \times(1,0 \mathrm{Gbps} / 16) \times 16=0,9 \mathrm{Gbps}$, o tráfego total se aproxima do máximo, 1,0 Gbps. Acima de 1,0 Gbps, o buffer será intensamente utilizado alcançando o valor de saturação, a partir do qual pacotes passam a ser descartados.

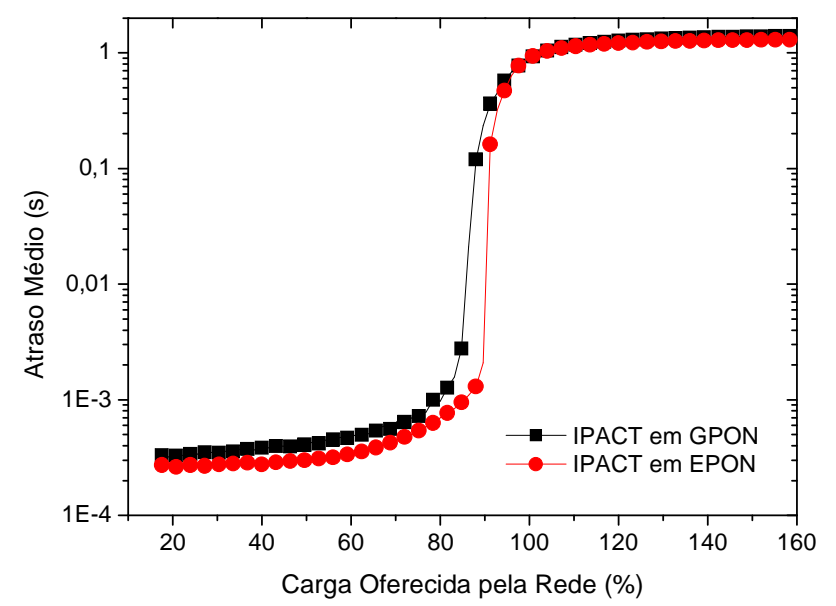

Figura 5. Comparação de desempenho do algoritmo IPACT em redes GPON e EPON. A carga oferecida pela rede é a carga de tráfego gerada por todas as ONUs.

Para cargas menores que $90 \%$ (900 Mbps), o atraso médio é menor que $1,15 \mathrm{~s}$ para a rede EPON e menor que $1,2 \mathrm{~s}$ para a rede GPON. Para cargas maiores que $90 \%$, este atraso se acentua alcançando o valor máximo $1,4 \mathrm{~s}$, indicando que a banda máxima disponível é alcançada.

Observamos nesta simulação do algoritmo IPACT que a rede GPON apresenta atraso maior que a rede EPON para carga até próxima de $100 \%$, pois o atraso na transmissão de mensagens gate e pacotes upstream são considerados. Para se transmitir uma mensagem equivalente à gate em uma rede GPON, é necessário que todas as ONUs informem o status de suas filas e componham o quadro upstream, fechando o 
ciclo de transmissão. Desta forma, as primeiras ONUs ficam ociosas com a espera do término de envio da mensagem upstream pela última ONU. Na rede EPON a mensagem gate é enviada às ONUs independentemente do término do ciclo, diminuindo o atraso na transmissão [7].

\section{Algoritmo para um Contêiner}

Nesta simulação consideramos uma rede GPON implementada com apenas um contêiner de tráfego e três diferentes tipos de SLAs que são distribuídos para as 16 ONUs, conforme mostra a Tabela 2. Desta forma, a realocação de banda de acordo com as prioridades estabelecidas nos SLAs fica enaltecida.

Tabela 2. SLAs e ONUs.

\begin{tabular}{ccc} 
SLA & Prioridade & ONUs \\
\hline 1 & Alta & 1 a 4 \\
2 & Média & 5 a 8 \\
3 & Baixa & 9 a 16 \\
\hline
\end{tabular}

O gerenciamento de banda é realizado pelo DBA, que aloca banda mínima (CIR) de $34 \mathrm{Mbps}$ para cada ONU. Assim, 34 Mbps $\times 16$ ONUs $=544$ Mbps total de banda garantida. Consequentemente, a EIR é $1250-544=706$ Mbps. Esta banda será alocada dinamicamente às ONUs com SLAs de maior prioridade.

Em nossa abordagem não há limitação de banda para esta utilização. As ONUs com SLA 1 podem utilizar toda banda EIR. Se ainda restar banda após a utilização, as ONUs com $\mathrm{SLA}_{2}$ poderão utilizar o restante e, em sequência, as com $\mathrm{SLA}_{3}$. No entanto, o padrão GPON de T-CONTs é obedecido também para a banda EIR.

Sendo a taxa de 1,25 Gbps distribuída entre as 16 ONUs, ela é alcançada para, aproximadamente, $78 \mathrm{Mbps}$ (16 ONUs $\times 78 \mathrm{Mbps}=1,25 \mathrm{Gbps})$, supondo que todas as ONUs solicitem a mesma banda. A Tabela 3 apresenta os dados que foram utilizados em todas as seguintes simulações.

Tabela 3. Parâmetros de simulação do algoritmo proposto. Descrição

\begin{tabular}{lc} 
Descrição & GPON \\
\hline Taxa de bit total (Gbps) & 1,25 \\
\hline Taxa de bit ONU (Mbps) & 100 \\
Número Total de ONUs & 16 \\
\hline Tamanho do buffer nas ONUs (MB) & 10 \\
Distância máxima entre OLT e ONUs $(\mathrm{km})$ & 20 \\
\hline Tamanho máximo do time slot (B) & 1215 \\
Tempo (bit) de guarda entre transmissões & 96 bit \\
Tempo máximo do ciclo de interrogação $(\mu \mathrm{s})$ & 125 \\
\hline
\end{tabular}

A Figura 6 ilustra o atraso médio dos pacotes para três tipos de SLAs e apenas um contêiner. Esta simulação é realizada para enaltecer a distribuição de prioridades (SLAs) entre as ONUs. Quando a carga da rede nas ONUs alcança $70 \%$ do valor máximo, o atraso médio dos quadros do $\mathrm{SLA}_{3}$ (prioridade baixa) começa a aumentar acentuadamente, alcançando o atraso de 0,217 s. Como o algoritmo DBA prioriza os SLAs de maior prioridade, a banda alocada às ONUs de $\mathrm{SLA}_{3}$ fica cada vez menor. Para o $\mathrm{SLA}_{2}$ (prioridade média), a saturação ocorre a partir de $90 \%$, com atraso de $36 \mathrm{~ms}$, porque maior quantidade de banda é alocada para o $\mathrm{SLA}_{1}$, que tem prioridade sob os demais. $\mathrm{O}$ atraso máximo alcançado para o $\mathrm{SLA}_{1}$ (prioridade alta) é $0,125 \mathrm{~ms}$.

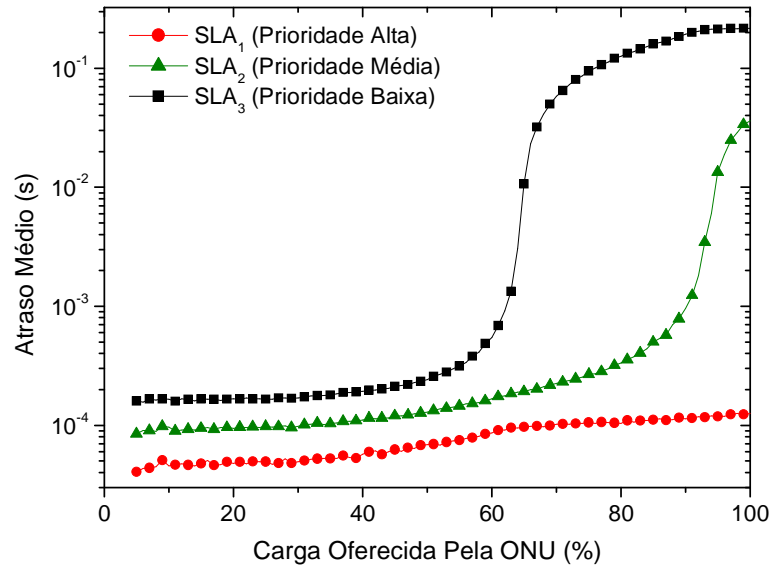

Figura 6. Atraso médio de pacotes em função da carga oferecida para os 3 SLAs e um contêiner.

Em relação aos resultados exibidos pelo algoritmo DMB [8], em que os autores utilizam distribuição de banda com base em pesos, os atrasos de pacotes das prioridades 1 e 2 de nossa abordagem são menores (Figura 6), porque não limitamos a quantidade de banda não utilizada que os SLAs podem dispor. No entanto, ressaltamos que as duas abordagens, tanto a de [8] quanto a nossa, são heurísticas, significando que a adoção deste tipo de solução depende de outros fatores como remuneração de investimento da operadora.

\section{Algoritmo para Quatro Contêineres}

A partir desta subseção, as simulações se referem a uma rede GPON com 4 contêineres (o T-CONT 5 não é utilizado) e três tipos de SLAs distintos, conforme mostra a Tabela 2 .

A Figura 7 mostra o atraso médio de pacotes para os $4 \mathrm{~T}$ CONTs e SLA 1 (ONUs 1 a 4). Para uma determinada carga, os atrasos médios aumentam à medida que a prioridade do T-CONT diminui. Notar que a partir de $78 \%$, o atraso para o T-CONT 1 permanece constante e os demais T-CONTs têm um aumento significativo. É porque toda banda é alocada para o T-CONT 1 quando a carga da rede satura (16 ONUs $\times 78 \mathrm{Mbps}=1,25 \mathrm{Gbps})$. A Tabela 4 resume os valores de atraso médio de pacotes para $100 \%$ de carga por ONU.

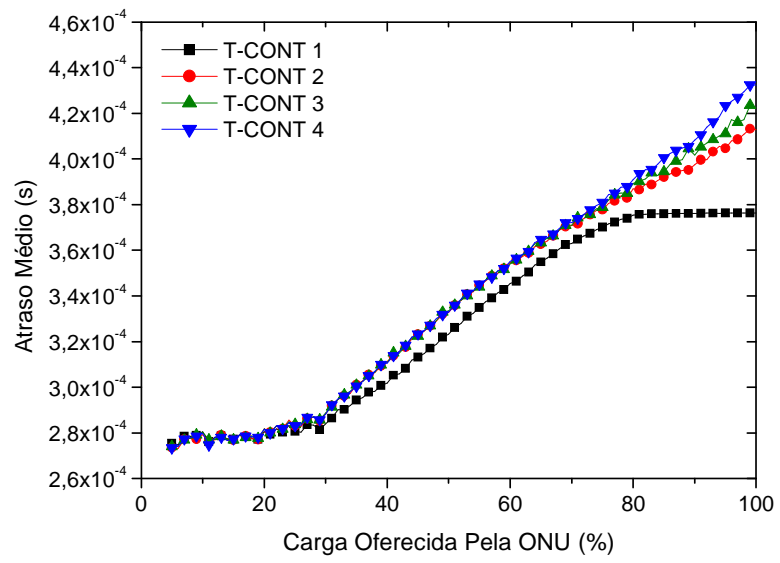

Figura 7. Atraso médio dos T-CONTs de prioridade alta $\left(\mathrm{SLA}_{1}\right)$.

A Figura 8 mostra o atraso médio de pacotes para a prioridade média $\left(\mathrm{SLA}_{2}\right)$. Para valores elevados de carga, os atrasos se diferenciam porque a alocação de banda prioriza os T-CONTs de maior prioridade. Os valores de atraso médio são maiores quando comparados com os mostrados na Figura 7 porque a banda é alocada prioritariamente para o 
SLA $_{1}$ e depois para os demais SLAs. A Tabela 4 resume os valores de atraso médio de pacotes para $100 \%$ de carga por ONU.

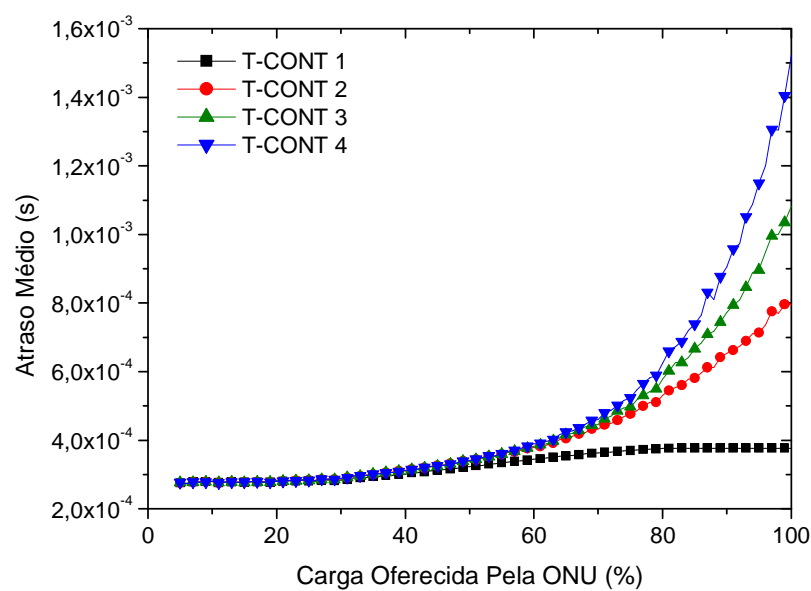

Figura 8. Atraso médio dos T-CONTs de prioridade média $\left(\mathrm{SLA}_{2}\right)$.

A Figura 9 mostra o atraso médio dos quadros em função da carga por ONU para a prioridade baixa $\left(\mathrm{SLA}_{3}\right)$. O DBA aloca maior banda para os SLAs de maior prioridade. Portanto, o $\mathrm{SLA}_{3}$ tem o maior atraso dentre eles. Quando a carga da ONU alcança 75\%, a capacidade da rede está perto de ser atingido, acentuando o atraso. A Tabela 4 resume os valores de atraso médio de pacotes para $100 \%$ de carga por ONU.

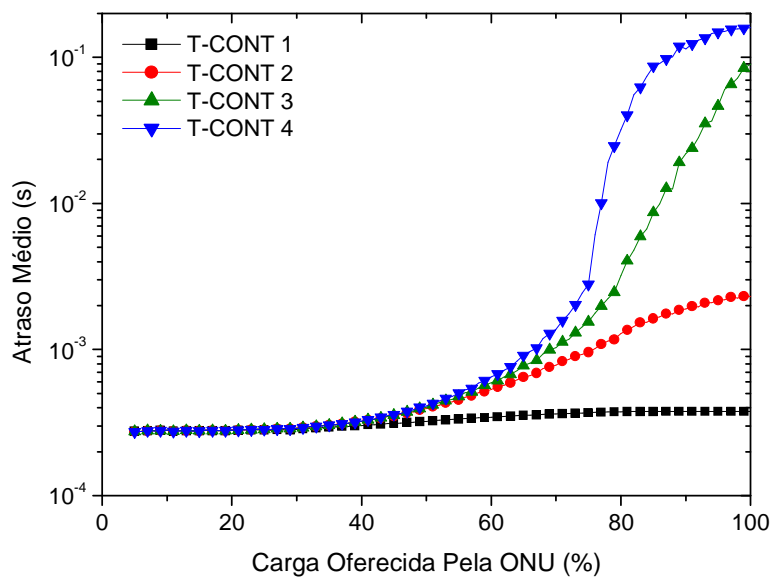

Figura 9. Atraso médio dos T-CONTs de prioridade baixa $\left(\mathrm{SLA}_{3}\right)$.

Tabela 4. Atraso médio dos T-CONTs dos SLAs para 100\% de carga por ONU.

\begin{tabular}{cccc}
\multirow{2}{*}{ T-CONT } & \multicolumn{3}{c}{ Atraso Médio (ms) } \\
\cline { 2 - 4 } & $\mathrm{SLA}_{1}$ (Alta) & $\mathrm{SLA}_{2}$ (Média) & $\mathrm{SLA}_{3}$ (Baixa) \\
\hline 1 & 0,3763 & 0,3769 & 0,3774 \\
2 & 0,4129 & 0,7969 & 2,31 \\
3 & 0,4224 & 1,08 & 89,9 \\
4 & 0,4324 & 1,52 & 159,69 \\
\hline
\end{tabular}

A Figura 10 resume o atraso médio dos três tipos de SLAs para o T-CONT 3, mostrados nas Figuras 7-9. As ONUs que pertencem ao SLA de maior prioridade dispõem de mais banda e, consequentemente, o tráfego experimenta menor atraso. Para cargas menores que 50\%, o atraso dos pacotes referentes aos SLAs estão bem próximos. Entre 50\% e 70\%, o atraso do $\mathrm{SLA}_{3}$ começa a aumentar em relação aos outros porque a banda passa a ser alocada prioritariamente para o $\mathrm{SLA}_{1}$ e $\mathrm{SLA}_{2}$. Para cargas maiores que $70 \%$, o atraso do $\mathrm{SLA}_{2}$ aumenta, o atraso do $\mathrm{SLA}_{3}$ acentua-se e o do $\mathrm{SLA}_{1}$ permanece aproximadamente constante. Neste caso, o algoritmo realoca quase toda banda não utilizada para o $\mathrm{SLA}_{1}$, alocando o restante da banda não utilizada para os demais SLAs.

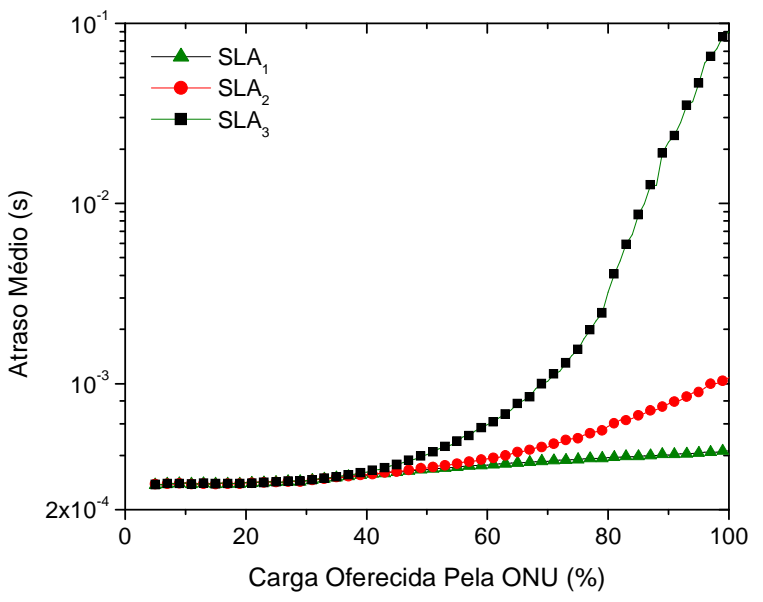

Figura 10. Atraso médio dos três tipos de SLA para o T-CONT 3.

\section{CONCLUSÕES}

Neste trabalho descrevemos um algoritmo de alocação dinâmica de banda para rede de acesso via fibra óptica padrão GPON e taxa máxima 1,25 Gbps. O padrão GPON reúne tráfego semelhante gerado nas ONUs em 5 contêineres que fornecem prioridade para transmissão upstream. O algoritmo proposto aloca banda mínima para as ONUs e realoca a banda que não foi utilizada de acordo com três SLAs. Os resultados numéricos mostram a eficiência e versatilidade do algoritmo proposto. Pesquisa futura inclui avaliação de taxas para o estabelecimento de diversos SLAs e ampliação de requisitos de QoS.

\section{REFERÊNCIAS}

[1] R. W. Heron et al., "Technology Innovations and Architecture Solutions for the Next-Generation Optical Access Network", Bell Labs Technical Journal 13(1), 163-182 (2008).

[2] Cedric F. Lam, "Passive Optical Network: Principles and Practice", Elsevier Inc, 2007.

[3] https://www.ieeecommunities.org/epon.

[4] http://www.itu.int/rec/T-REC-G/e.

[5] ITU-T Recommendation G.984.3, "Gigabit-capable passive optical networks (GPON): transmission convergence layer specification," 2008.

[6] Ivica Cale, A. Salihovic e Matija Ivekovic, "Gigabit Passive Optical Network - GPON", Proceedings of the ITI $200729^{\text {th }}$ Int. Conf. on information Technology Interfaces, Cavtat, Croatia, Junho 25-28, 2007.

[7] Ching-Hung Chang, "Dynamic Bandwidth Allocation MAC Protocols for Gigabit-capable Passive Optical Networks", thesis, University of Hertfordshire, Julho de 2008.

[8] C.-H. Chang, P. Kourtessis, and J. M. Senior, "GPON service level agreement based dynamic bandwidth assignment protocol," Journal of Electronics Letters,vol. 42, pp. 1173-1174, 2006.

[9] H. C. Leligou, Ch. Linardakis, K. Kanonakis, J. D Angelopoulos e Th. Orphanoudakis, "Efficient medium arbitration of FSANcompliant GPONs: Research Articles", International Journal of Communication Systems, volume 19, pp. 603-617, Junho 2006.

[10] Jiang, J. Handley, M.R. Senior e J.M., "Dynamic bandwidth assignment MAC protocol for differentiated services over GPON", Electronics Letters, 25th, Vol. 42, Maio 2006.

[11] G. Kramer, B. Mukherjee, e G. Pesavento, "IPACT a dynamic protocol for an Ethernet PON (EPON)," Communications Magazine, IEEE, vol. 40, pp. 74-80, 2002.

[12] Marek Hajduczenia, Henrique J. da Silva, e Paulo P. Monteiro, "EPON versus APON and GPON: a detailed performance comparison", Journal of Optical Networking, Vol. 5, Issue 4, pp. 298 319, Abril, 2006. 